\title{
Long-Term Effects of Two Psychological Interventions on Physical Exercise and Self-Regulation Following Coronary Rehabilitation
}

\author{
Falko F. Sniehotta, Urte Scholz, Ralf Schwarzer, Bärbel Fuhrmann, \\ Ulrich Kiwus, and Heinz Völler
}

\begin{abstract}
In cardiac rehabilitation programs, patients learn how to adopt a healthier lifestyle, including regular, strenuous physical activity. Long-term success is only modest despite good intentions. To improve exercise adherence, a 3-group experiment was designed that included innovative psychological interventions. All 3 groups underwent a standard care rehabilitation program. Patients in the 2 treatment groups were instructed not only to produce detailed action plans but also to develop barrier-focused mental strategies. On top of this, in 1 of these groups a weekly diary was kept for 6 weeks to increase a sense of action control. At the end of a standard cardiac rehabilitation program, 240 patients were randomly assigned to these treatment groups plus a standard care control group. Treatments resulted in more physical activity at follow-up and better adherence to recommended levels of exercise intensity. Moreover, self-regulatory skills such as planning and action control were improved by the treatments. Follow-up analyses demonstrated the mediating mechanisms of selfregulatory skills in the process of physical exercise maintenance. Findings imply that interventions targeting self-regulatory skills can enable postrehabilitation patients to reduce behavioral risk factors and facilitate intended lifestyle changes.
\end{abstract}

Key words: physical activity, physical exercise, adherence, planning, intentions, cardiac rehabilitation

Physical exercise plays a major role in the prevention and rehabilitation of coronary heart disease (CHD). Lack of physical activity is a major and independent CHD risk factor (Donker, 2000; Grundy, Pasternak, Greenland, Smith, \& Fuster, 1999). Regular physical exercise not only prevents the development of CHD but also is associated with lower mortality, lower relapse rates, and reduced symptoms after the manifestation of CHD (cf. Thompson et al., 2003). A recent meta-analysis found that long-term supervised exercise reduces mortality in CHD patients by $31 \%$ (Jolliffe et al., 2003). Furthermore, regular aerobic exercise may lead to a remission of coronary stenosis (Ornish et al., 1998). Physical exercise is therefore a

Falko F. Sniehotta, University of Aberdeen, UK; Urte Scholz and Ralf Schwarzer, Free University Berlin, Germany; Bärbel Fuhrmann and Ulrich Kiwus, Rehabilitationsklinik Seehof, Teltow, Germany; Heinz Völler, Klinik am See, Rüdersdorf, Germany.

We thank the patients and staff of the Brandenburgklinik in Bernau, the Klinik am See in Rüdersorf, and the Rehabilitationsklinik Seehof der BfA in Teltow. We would also like to thank James E. Maddux and Benjamin Schüz for comments on an earlier draft of this article.

Correspondence concerning this article should be addressed to Falko F. Sniehotta, University of Aberdeen, School of Psychology, College of Life Sciences and Medicine, King's College, William Guild Building, Aberdeen, AB24 2UB, United Kingdom. E-mail: f.sniehotta@abdn.ac.uk key factor in cardiac rehabilitation programs and highly recommended to patients after discharge from the rehabilitation center (Ades, 2001; De Backer et al., 2003).

In Germany, cardiac rehabilitation is mainly provided on an in-patient basis over 3 to 4 weeks. All patients undergo an initial exercise stress test and are thoroughly checked by the physicians in the rehabilitation center. The results of the stress test are used to design an individualized daily exercise program in accordance with the guidelines of the German Cardiac Society (Deutsche Gesellschaft für Kardiologie, 2001). These state that CHD patients should engage in regular aerobic exercise (e.g., walking, running, biking) three to seven times per week, for 30 to $45 \mathrm{~min}$ with $40 \%-60 \%$ of their maximum heart capacity. Following discharge, participants are advised to (a) engage in regular strenuous exercise with a strain level comparable to their exercise in the rehabilitation center, (b) increase their physical exercise in general, and (c) participate in a weekly cardiac training group, supervised by a cardiologist.

Nevertheless, changes in behavioral risk factors for CHD are difficult to achieve and to maintain. Despite the enhanced risk awareness of cardiac patients, many of them proceed with an unhealthy and sedentary lifestyle (Dusseldorp, Van Elderen, Maes, Meulman, \& 
Kraaij, 1999; Johnston, 1999). In a study with patients who participated in a 3 -week rehabilitation program following an acute cardiac event, only $25 \%$ of the patients adhered to the prescribed training program at 1-year follow up (Willich et al., 2001). Attrition from postrehabilitation physical exercise programs is generally high and increases over time (Moore, Ruland, Pashkow, \& Blackburn, 1998; Oldridge, 1991).

\section{Social-Cognitive Models of Health Behavior and the Control of Action}

Intention-based social-cognition models assume that behavior is directly predicted by two cognitions, behavioral intention and perceived behavioral control (Ajzen, 1991) or self-efficacy (Bandura, 1997). The application of these models to lifestyle changes in CHD patients faces a key problem: Following diagnosis and treatment of CHD, virtually all patients report strong behavioral intentions and high self-efficacy to engage in regular physical exercise (Blanchard, Courneya, Rodgers, Daub, \& Knapik; 2002; Johnston, Johnston, Pollard, Kinmonth, \& Mant, 2004; Sniehotta, Scholz, \& Schwarzer, 2005). Corresponding subsequent behavior, however, is seldom performed. Understanding how and why people do or do not change their health behavior requires a distinction between motivational processes of intention formation and volitional processes of action initiation and maintenance (Kuhl, 1986; Schwarzer, 1992). Several recent reviews of health-behavior models agree that models focusing on motivational processes only need to be augmented by a volitional stage to better explain individual differences in health-behavior change and to design interventions for health promotion (Abraham, Sheeran, \& Johnston, 1998; Bagozzi \& Edwards, 2000; Conner \& Armitage, 1998; Gollwitzer \& Oettingen, 1998; Sutton, 1998).

Acting on intentions that address nonhedonistic behavior (not associated with immediate gratification) requires volitional control (Baumeister, Heatherton, \& Tice, 1994). Without volitional control, behavior would be determined by learned or innate reactions to situational cues or inner states. Volitional control is applied to alter one's spontaneous reaction by the use of appropriate self-regulatory strategies (Abraham, et al., 1998). This study examined two interventions addressing volitional self-regulatory strategies to foster the initiation and maintenance of physical exercise: planning and action control.

\section{Planning}

Planning refers to a prospective self-regulatory strategy, in which persons link behavioral responses to specific situations to achieve certain goals. How, where, and when to implement actions and how to cope with obstacles are planned in advanced. This can prevent inappropriate, spontaneous, and premature in situ reactions. Appropriate behavioral responses can be selected and assigned to the most suitable situation or opportunity. Planning helps individuals to make situational target cues more easily accessible and critical situations more detectable because individuals form an active mental representation of the target situation (Gollwitzer, 1999).

Two kinds of planning can be distinguished: action planning and coping planning. Action planning (implementation intentions; Gollwitzer, 1999) specifies when, where, and how to act (Leventhal, Singer, \& Jones, 1965; Sheeran \& Orbell, 1999). Action planning can thereby build up contingencies between situational cues and intended behavior. In the presence of such cues, intended behavior can be initiated without the need of conscious acts. Coping planning (Sniehotta, Scholz, \& Schwarzer, in press) pertains to the anticipation of personal risk situations (i.e., situations characterized by barriers that endanger the execution of the intended behavior) and planning coping responses in detail. Coping planning, thus, is a barrier-focused strategic mental simulation. It can break automatic links between certain (risk) situations and unwanted responses by making these situations more salient (Sniehotta, Schwarzer, Scholz, \& Schüz, 2005) and preparing for successful coping.

Interventions for action planning have been successfully applied to different health-related lifestyles such as maintaining a healthy diet (Verplanken \& Faes, 1999), pursuing physical activity (Milne, Orbell, \& Sheeran, 2002), and regulating the consumption of alcohol (Murgraff, White, \& Phillips, 1996). These studies, however, have examined the target behavior for only a 1-week or 2 -week period. Two recent studies with orthopedic and coronary rehabilitation patients found that planning interventions were successful in changing habitual pattern in physical exercise over longer time periods of 1 month (Lippke, Ziegelmann, \& Schwarzer, 2004) and 2 months, respectively, (Sniehotta, Scholz, et al., in press) when participants formed action plans together with coping plans.

\section{Action Control}

Self-regulation refers to any efforts undertaken to alter one's behavior (Baumeister et al., 1994; Scheier \& Carver, 2003). Action control (Kuhl, 1986; Sniehotta, Scholz, et al., 2005) is activated when a behavioral intention has been formed whose enactment and maintenance is effortful and involves nonhedonistic behavior. Action control is a subfacet of self-regulation and self-control, aiming to control intentional behavior. It consists of the successful orchestration of three processes that can be derived from the 
self-regulation model by Carver and Scheier (1998). First, persons willing to control their actions must be aware of their own standards, for example, exercising three times a week for $45 \mathrm{~min}$ at the gym, as a benchmark to regulate one's actions. Second, self-monitoring is required to evaluate one's ongoing behavior against one's standards. Third, when discrepancies between action and standards occur, regulatory means to reduce the discrepancy (e.g., those specified in one's plans) must be taken and regulatory effort must be spent. Self-monitoring, awareness of standards, and regulatory effort are conceptually distinct processes. However, successful action control results from the interplay of these processes (Sniehotta, Nagy, Scholz, \& Schwarzer, in press). The processes are therefore highly interrelated. The more action control individuals administer, the more likely they are to successfully alter their behavior in accordance to their behavioral intentions (Kuhl, 1986; Sniehotta, Scholz, et al., 2005). Some theorists view action control as dispositional and therefore stable over time (e.g., Baumeister et al., 1994; Mischel, Shoda, \& Peake, 1988; Schröder \& Schwarzer, 2005). Nevertheless, interventions fostering self-monitoring (Kanfer \& Karoly, 1982) and repeated training of self-control techniques (e.g., by keeping diaries) can enhance action control (Muraven, Baumeister, \& Tice, 1999).

The purpose of this study was to examine two interventions addressing self-regulatory skills in their effects on changes in physical exercise and selfregulatory cognitions over a 4-month period following discharge from rehabilitation compared to a standard care control group.

\section{Method}

\section{Participants and Procedure}

Participants were 240 patients with CHD from three rehabilitation centers near Berlin, Germany. They underwent a 3- to 4-week cardiac rehabilitation treatment in an in-patient setting that followed the acute medical care in a regular hospital. During rehabilitation, all participants attended guided exercise sessions such as bicycle ergometer training with individualized strain levels at least three to five times a week as well as three to five weekly sessions of walking or nordic walking. In addition, they participated in group or individual gymnastic exercises and in some cases weight training (Bjarnason-Wehrens, et al., 2004). Following discharge, participants were recommended by their physicians to (a) engage in regular strenuous exercise comparable to the exercise strain in the rehabilitation center, (b) increase their physical exercise in general, and (c) participate in a cardiac sports group. To in- crease compliance to these recommendations, attitudes, knowledge about CHD and its rehabilitation, and motivation were addressed in psychoeducational classes during rehabilitation but the recommendations were not reinforced over the time following (Dietz \& Rauch, 2003).

Participants were informed about the study and were assured confidentiality of all medical and psychological data. Furthermore, they were informed that the participation was voluntary and unpaid. Every participant was given a personal code to match the data of the questionnaires of the three waves to ensure anonymity. All participants were treated according to the American Psychological Association (APA) ethical guidelines (APA, 2002). The first questionnaire was completed in the 2nd week of participants' stay in the rehabilitation center. Two hundred seventeen participants $(90.4 \%)$ completed a Time 2 follow-up questionnaire by mail 2 months after discharge from the rehabilitation center and $199(82.9 \%)$ completed a Time 3 follow-up questionnaire 4 months later.

Participants were randomly assigned to a planning group, a planning plus diary group, or a standard care control group. Participants of all groups filled out the three questionnaires. Additionally, participants of the two treatment groups took part in an individual planning session during the last week of their stay in the rehabilitation clinic. In addition to that, participants of the planning plus diary group kept a weekly diary for 6 weeks after discharge from the rehabilitation center.

The mean age of participants in the initial sample was 57.7 years $(S D=10.3)$ with a range from $31-80$ years, and $195(81.5 \%)$ of the participants were men. The majority was married or living with a partner (193 $=80.4 \%), 21(7.5 \%)$ persons were single, $18(7.5 \%) \mathrm{di}-$ vorced, and 8 persons $(3.3 \%)$ were widowed. Thirty-four patients $(14.2 \%)$ did not have children. Sixty-nine participants reported a maximum of 9 years of school education (28.8\%), 84 participants (35\%) had 10 years, and $84(35 \%)$ had 12 or 13 years of schooling. Approximately half of the sample was currently still employed $(114 ; 47.5 \%)$. In terms of exercise behavior before the acute treatment, $115(47.7 \%)$ of the patients reported a completely sedentary lifestyle (i.e., zero exercise activity).

\section{Measures}

The questionnaires contained several psychometric scales in addition to demographic information. All item examples given in the following were translated from German. Each item was scored on a 4-point scale from 1 (completely disagree) to 4 (totally agree).

Behavioral intentions, self-efficacy, and planning were assessed at all times of measurement. Behavioral intentions were assessed by six items taken from Fuchs 
(1997) and adapted to the special sample of cardiac rehabilitation patients. The stem "I intend to ..." was followed by a list of recommended activities, for example, " ... be regularly physically active for a minimum of 30 minutes at least three times a week." Self-efficacy was assessed by four items from the Exercise Self-Efficacy Scale from Fuchs (1997) and adapted slightly to the coronary rehabilitation setting (e.g." "I am able to exercise at least three times per week for at least thirty minutes.").

Planning was assessed using the two planning subscales by Sniehotta, Schwarzer, et al. (2005). Action planning was measured by five items. The item stem "I have made a detailed plan regarding ... " was followed by the items (a) "... when to exercise," (b) "... where to exercise," (c) "... how to exercise," and (d) "... how often to exercise." For the assessment of coping planning, the item stem "I have made a detailed plan regarding ..." was followed by five items, for example "... what to do if something interferes with my plans."

Action control was assessed with a scale developed by Sniehotta, Scholz, et al. (2005) at Time 2 and Time 3 . Two items each addressed the different action control facets comparative self-monitoring, awareness of standards, and self-regulatory effort. The items were introduced by the stem "During the last four weeks, I have ..." (a) "... constantly monitored myself whether I exercise frequently enough," (b) "... watched carefully that I trained for at least 30 minutes with the recommended strain per unit," (c) “. .. had my exercise intention often on my mind," (d) " ... always been aware of my prescribed training program," (e) "... really tried to exercise regularly," and (f) " ... tried my best to act in accordance to my standards." Comparative self-monitoring, awareness of standards, and self-regulatory effort are facets of an action control process and they are therefore added to a single scale. Due to the hospitalization, the measure was not assessed at Time 1.

For the assessment of general physical exercise, the Kaiser Physical Activity Survey (Ainsworth, Sternfeld, Richardson, \& Jackson, et al., 2000) was adapted to the special characteristics of a cardiac patient sample. Five domains of recommended physical exercise were taken into consideration: (a) vigorous exercise (e.g., swimming); (b) fitness activities (e.g., gymnastics); (c) game sports, such as volleyball or tennis; (d) moderate exercise to train muscle strength; and (e) other prescribed exercises. At Time 1 participants were asked to indicate how often per week and how long per unit they engaged on average in each domain in the time period before their acute CHD event. At Time 2 and Time 3, participants were asked how often per week and how long per unit they engaged on average in each domain during the past 4 weeks. For each domain, the amount of exercise was computed by multiplying the frequency of exercise sessions per week with minutes per session (see also Bernstein et al., 1998 and Lippke et al., 2004 for similar approaches). To assess the condition-specific recommended strenuous exercise at Time 2 and Time 3, participants were asked to indicate how many sessions and how long per session on average these activities equaled the strain of their exercise program in the rehabilitation center. This measure was assessed at Time 2 and Time 3 only, because it refers to exercises conducted in accordance to the strain levels that the patients have experienced during the rehabilitation.

Measures of physical exercise based on the product of "frequency of sessions" and "minutes per session" usually generate skewed distributions in patients' samples because most patients report only minor levels of exercise or none at all. This was also the case in this study. The exercise data were transformed by a natural $\log$ transformation to avoid violating the assumptions for the use of parametric statistics (Bland \& Altman, 1996).

Finally, it was recorded whether or not patients participated in cardiac training groups within the first 4 months after discharge, as recommended by the German Society for Prevention and Rehabilitation of Coronary Heart Diseases.

\section{Experimental Treatment I: Planning Intervention}

Participants received a planning booklet with two planning sheets for action plans and for coping plans, respectively (see Sniehotta, Scholz, et al., in press). In case of questions or misunderstandings, they were invited to turn to the trained interviewers. The planning sheet for action plans opened with the instruction "Please think about the time after discharge from the rehabilitation center. When, where and how do you plan to be physically active? Please write down your plans in the following table. The more precise, concrete and personally you formulate your plans, the more they can help you." The table contained three rows labeled Plan 1, Plan 2, and Plan 3. The columns were headed with "when," "where," "how," and "with whom." The planning sheet for coping plans opened with the instruction: "Which obstacles or barriers might interfere with the implementation of your exercise plans? How could you successfully cope with such problems? Please write down your plans in the following table. The more precise, concrete and personally you formulate your plans, the more they will help you." The planning booklet ended with the instruction to "Memorize your plans carefully. Visualize the situations and your planned actions and make a firm commitment to act as planned." 


\section{Experimental Treatment II Personalized Weekly Diary Intervention}

Participants in the planning plus diary group took part in the planning intervention. Additionally, they received by mail six weekly diaries after discharge, tailored to individual requirements. In each diary participants received copies of their own personal plans previously formulated in the planning intervention. For each plan, participants were asked how often during the last 7 days the situation specified in the plan had occurred, how often they had acted in accordance with their own plan, and how optimistic they felt about adherence to their plan over the next week. Participants completed the diary and sent it back to the university in a provided self-addressed envelope. If participants wanted to change a plan, the modified plan was included in the diary for the following week.

\section{Rationale}

It was expected that the planning intervention would improve levels of action planning and coping planning. Keeping a diary was hypothesized to result in higher levels of action control. However, no effects of the two interventions on behavioral intentions were expected, because the interventions were explicitly designed as postintentional and volitional. Improving self-regulatory skills should also result in more selfefficacy in participants who underwent the treatments as an experimental side effect. Furthermore, the enhanced self-regulatory skills were hypothesized to result in more general physical exercise, more recommended strenuous exercise, and better attendance of cardiac training groups.

\section{Analyses}

We examined the effectiveness of the interventions by conducting analyses of covariance (ANCOVAs) using the experimental group as a between-subjects factor and controlling for gender, age, and, if available, the Time 1 baseline measure. Dependent variables were the Time 2 and Time 3 motivational, volitional, and behavioral measures. Motivational and volitional measures that exhibited significant changes through the interventions were entered as covariates in the ANCOVAs on Time 3 measures of physical exercise to test for mediation. Mediation can be assumed if the effect on Time 3 exercise measures is significant and the Time 2 covariates have significant effects on the exercise measures and if the initial group effect is no longer significant, after controlling for the covariates. Finally, group differences in the attendance to cardiac training groups were tested by $\chi^{2}$ tests.

\section{Results}

Randomization checks conducted by analyses of variance (ANOVAs) and chi-square tests revealed that the control group and the two experimental groups did not differ in terms of any Time 1 measures or demographic or medical variables.

The reliability coefficients for all measures were satisfactory, ranging from .81 to .92 . Retest reliabilities of the motivational and volitional measures were high, ranging from .72 for action control (Time 2 to Time 3 ) to .38 for action planning from Time 1 to Time 2 . In general, the retest reliabilities of all measures were slightly higher from Time 2 to Time 3 than they were from Time 1 and Time 2 . All measures were significantly intercorrelated. Nevertheless, all scales, especially those assessing volitional constructs were very homogeneous and provided sufficient discriminant validity for further analyses.

Participants reported high behavioral intentions ( $M$ $=3.43, S D=.51)$, self-efficacy $(M=3.33, S D=.61)$, and action planning $(M=3.16, S D=.90)$ and comparatively lower levels of coping planning $(M=2.51, S D=$ $.91)$ at Time 1 . Patients retrospectively reported an average of $69.2(S D=109.0)$ min of weekly engagement in general physical exercise prior to their acute treatment.

\section{Effects of the Interventions}

Table 1 presents the results of ANCOVAs analyzing the Time 2 motivational, volitional, and behavioral variables, controlling for age and sex, and for the baseline assessed at Time 1, if available.

As hypothesized, coping planning and action control were significantly higher in the two treatment groups than in the control group. Although both experimental groups showed higher levels in coping planning, the planning plus diary group was highest in action control. This follows the rationale of the experimental design. The effect of the treatment on action control was the strongest one found in these analyses. In contradiction to the hypotheses, action planning was not increased by the planning intervention. All groups reported very high levels of action planning 2 months after discharge from the rehabilitation $(>3.2$ on a scale ranging from 1 to 4 ).

Behavioral intentions and perceived self-efficacy were also affected by the interventions. Although both intervention groups showed higher levels in behavioral intentions at Time 2, only participants in the planning plus diary group reported higher levels in self-efficacy than those in the control group.

The two behavioral outcome measures also revealed group differences. Time 2 general physical exercise in the planning group was only slightly higher 
Table 1. Estimated Marginal Means (Controlled for Baseline, Age, and Sex) and Standard Errors for Time 2 Measures of Action Planning, Coping Planning, Behavioral Intentions, Exercise Self-Efficacy, and General Physical Exercise, and (Controlled for Age and Sex) Action Control and Exercise Adherence (F values and $\eta^{2}$ From ANCOVAs)

\begin{tabular}{|c|c|c|c|c|c|c|c|c|c|}
\hline & \multicolumn{2}{|c|}{ Control Group ${ }^{a}$} & \multicolumn{2}{|c|}{ Planning Group $b$} & \multicolumn{2}{|c|}{ Planning Plus Diary Group ${ }^{c}$} & \multirow[b]{2}{*}{ Contrasts } & \multirow[b]{2}{*}{ F } & \multirow[b]{2}{*}{$\eta^{2}$} \\
\hline & $M$ & $S E$ & $M$ & $S E$ & $M$ & $S E$ & & & \\
\hline Self-efficacy & 3.26 & 0.05 & 3.35 & 0.06 & 3.49 & 0.06 & $\mathrm{CO}<\mathrm{PDG}$ & $F(2,212)=4.07^{*}$ & .04 \\
\hline Behavioral intentions & 3.3 & 0.05 & 3.45 & 0.06 & 3.52 & 0.05 & $\mathrm{CO}<\mathrm{PG}, \mathrm{PDG}$ & $F(2,212)=5.17 * * *$ & .05 \\
\hline Action planning & 3.26 & 0.08 & 3.32 & 0.10 & 3.33 & 0.09 & - & $F(2,212)=0.18$ & .00 \\
\hline Coping planning & 2.63 & 0.08 & 2.92 & 0.09 & 2.94 & 0.09 & $\mathrm{CO}<\mathrm{PG}, \mathrm{PDG}$ & $F(2,212)=4.27 *$ & .04 \\
\hline Action control & 2.99 & 0.08 & 3.17 & 0.09 & 3.42 & 0.09 & $\mathrm{CO}<\mathrm{PDG}$ & $F(2,213)=7.08 * *$ & .06 \\
\hline General physical exercise $^{d}$ & 3.65 & 0.21 & 4.45 & 0.25 & 4.25 & 0.23 & $\mathrm{CO}<\mathrm{PG}$ & $F(2,212)=3.41 *$ & .03 \\
\hline Recommended strenuous exercise ${ }^{d}$ & $\begin{array}{c}{[121.26 \mathrm{~min}]} \\
3.11 \\
{[75.47 \mathrm{~min}]}\end{array}$ & 0.22 & $\begin{array}{c}\text { [182.92 min] } \\
3.72 \\
{[100.46 \mathrm{~min}]}\end{array}$ & 0.26 & $\begin{array}{c}\text { [150.72 } \mathrm{min}] \\
3.87 \\
\text { [126.61 } \mathrm{min}]\end{array}$ & 0.24 & $\mathrm{CO}<\mathrm{PDG}$ & $F(2,213)=3.13 *$ & .03 \\
\hline
\end{tabular}

Note. $S E=$ standard error; $\mathrm{CO}=$ control group; $\mathrm{PG}=$ Planning group; $\mathrm{PDG}=\mathrm{Planning}$ plus diary group.

${ }^{a} n=85, b_{n}=62 .{ }^{c} n=71$. dog-transformed exercise measures and equivalents in minutes a week.

$*^{*} p<.05 . *{ }^{*} p<.01$. 
than in the planning plus diary group but significantly higher than in the control group. Recommended strenuous exercise was highest in the planning plus diary group.

\section{Long-Term Effects}

To test long-term effects of the interventions, similar ANCOVAs as for Time 2 measures were conducted for Time 3 measures as outcomes. Table 2 presents the results of these ANCOVAs for the motivational, volitional, and behavioral variables, controlling for age and sex, and for the baseline assessed at Time 1, if available.

The pattern of results for the two measures of physical exercise slightly diverges at Time 3 . Although the broader general physical exercise measure was no longer affected by group differences at Time 3 , the effects for the more specific measures of recommended strenuous exercise increased. These analyses were based on $\log$-transformed exercise values. Figure 1 shows the development of exercise in all three groups across the three measurement points in time. Although the planning plus diary groups seems to report higher levels in recommended strenuous exercise at both follow-up occasions, as well as higher levels of general physical exercise at Time 3 than the planning group, none of these differences was found to be significant in subsequent contrast analyses of log-transformed values.

In general, the effects on motivational and volitional variables found for Time 2 remained stable for Time 3 measures. Self-efficacy, behavioral intentions, coping planning, and action control 4 months after discharge were still affected by the interventions. Minor changes were found in the contrast analyses. The planning plus diary group showed higher levels of action control than the two other groups. Behavioral intentions were higher in the planning group than they were in the control group and higher in the planning plus diary group than in the planning group.

To understand why volitional treatments affect behavioral intentions (that pertain to the prior motivation phase) post hoc repeated measures ANOVAs were conducted across all three measurement points in time, for behavioral intentions as the dependent variable and with treatment groups as the between-subjects factor. Results revealed that the interventions did not increase intentions but seemed to prevent a postrehabilitation decrease as found in the control group (Figure 2).

At Time 2, only the control group displayed a decrease in intentions, whereas both experimental groups remained highly motivated, $F(4,390)=2.83, p=.02$. In the planning group, a decrease in motivation was observed between Time 2 and Time 3, whereas participants in the planning plus diary group maintained their high intention levels over the 4-months period under study.
To examine whether the observed long-term effects on recommended strenuous exercise can be attributed to the hypothesized mediators, namely planning and action control, mediator analyses were conducted. Four variables met the first criterion for mediation, that is, revealed significant group differences at Time 2 . These were self-efficacy, behavioral intentions, coping planning, and action control. Two mediation models were tested. Model 1 adds Time 2 self-efficacy and behavioral intentions as covariates to the ANCOVA on Time 3 strenuous physical exercise that was reported in Table 2. This motivational mediation model draws a mediation path through the motivational processes of self-efficacy and intentions. The rationale of this study, however, assumes that the effects are mediated rather by volitional than by motivational processes. The second model tests the mediation through the volitional processes of coping planning and action control. This, on the contrary to the motivational Model 1, reflects the assumed mechanisms that lead to the long-term effects of the interventions.

In the first analysis, behavioral intentions had a strong effect on strenuous physical exercise, whereas self-efficacy did not. However, the group effect remained significant, indicating that intentions did not mediate the relation between the interventions and the long-term behavioral effects. In the second analysis, both covariates, coping planning and action control, showed strong effects on strenuous physical exercise. When both were controlled for, the group effect was no longer significant. Thus, the long-term effect of the interventions on strenuous physical exercise was fully accounted for by the experimentally increased levels of coping planning and action control (Table 3 ). This mediation pathway is in line with the hypothesized underlying processes of action control and coping planning.

Finally, the attendance at cardiac training groups was analyzed. Table 4 presents the frequencies of attenders and nonattenders within 4 months after discharge.

Overall, 67 (34\%) out of 199 participants attended a cardiac training group within 4 months after discharge from the rehabilitation center. The proportions of attenders are similar in the control group (29.1\%) and in the planning group (28.6\%) but much higher in the planning plus diary group (43.1\%). Differences in the proportions within experimental groups approached significance, $\chi^{2}=3.97, p=.09$; Fischer's exact test, $p=$ .05 . Comparing the planning plus diary group against the other two groups, the differences in cardiac training group attendance are significant $(p<.05)$.

\section{Discussion}

The purpose of this study was to examine the effects of two interventions addressing planning and action 
Table 2. Estimated Marginal Means (Controlled for Baseline, Age, and Sex) and Standard Errors for Time 3 Measures of Action Planning, Coping Planning, Behavioral Intentions, Exercise Self-Efficacy, and General Physical Exercise, and (Controlled for Age and Sex) Action Control and Exercise Adherence ( $F$ values and $\eta^{2} F r o m$ ANCOVAs)

\begin{tabular}{|c|c|c|c|c|c|c|c|c|c|}
\hline & \multicolumn{2}{|c|}{ Control Group ${ }^{a}$} & \multicolumn{2}{|c|}{ Planning Group ${ }^{b}$} & \multicolumn{2}{|c|}{ Planning Plus Diary Group ${ }^{\mathrm{c}}$} & \multirow[b]{2}{*}{ Contrasts } & \multirow[b]{2}{*}{$F$} & \multirow[b]{2}{*}{$\eta^{2}$} \\
\hline & $M$ & $S E$ & $M$ & $S E$ & $M$ & $S E$ & & & \\
\hline Self-efficacy & 3.15 & 0.06 & 3.33 & 0.07 & 3.46 & 0.06 & $\mathrm{CO}<\mathrm{PG} . \mathrm{PDG}$ & $F(2,194)=6.66^{*}$ & .06 \\
\hline Behavioral intentions & 3.20 & 0.06 & 3.24 & 0.07 & 3.47 & 0.07 & $\mathrm{CO}<\mathrm{PG}<\mathrm{PDG}$ & $F(2,194)=4.60$ * & .05 \\
\hline Action planning & 3.17 & 0.09 & 3.26 & 0.11 & 3.36 & 0.10 & - & $F(2,194)=1.07$ & .01 \\
\hline Coping planning & 2.64 & 0.09 & 2.93 & 0.10 & 2.94 & 0.09 & $\mathrm{CO}<\mathrm{PG}, \mathrm{PDG}$ & $F(2,194)=3.62^{*}$ & .04 \\
\hline Action control & 2.87 & 0.08 & 3.00 & 0.10 & 3.30 & 0.09 & $\mathrm{CO}, \mathrm{PG}<\mathrm{PDG}$ & $F(2,195)=6.34^{* * *}$ & .06 \\
\hline \multirow[t]{2}{*}{ General physical exercise ${ }^{a}$} & 3.88 & 2.20 & 3.87 & 0.26 & 4.35 & 0.24 & - & $F(2,194)=1.34$ & .01 \\
\hline & [129.95 min] & & [146.29 min] & & [168.98 $\mathrm{min}]$ & & & & \\
\hline Recommended strenuous exercise ${ }^{d}$ & $\begin{array}{c}2.79 \\
{[69.11 \mathrm{~min}]}\end{array}$ & 0.23 & $\begin{array}{c}3.69 \\
{[103.52 \mathrm{~min}]}\end{array}$ & 0.27 & $\begin{array}{c}3.98 \\
\text { [119.94 min] }\end{array}$ & 0.25 & $\mathrm{CO}<\mathrm{PG}, \mathrm{PDG}$ & $F(2,195)=6.73^{* *}$ & .07 \\
\hline
\end{tabular}

Note. $S E=$ standard error; $\mathrm{CO}=$ control group; $\mathrm{PG}=$ Planning group; $\mathrm{PDG}=$ Planning plus diary group.

${ }^{a} n=79 .{ }^{b} n=56 .{ }^{c} n=65$. 'Log-transformed exercise measures and equivalents in minutes a week.

${ }^{*} p<.05 . * * 0.01$ 

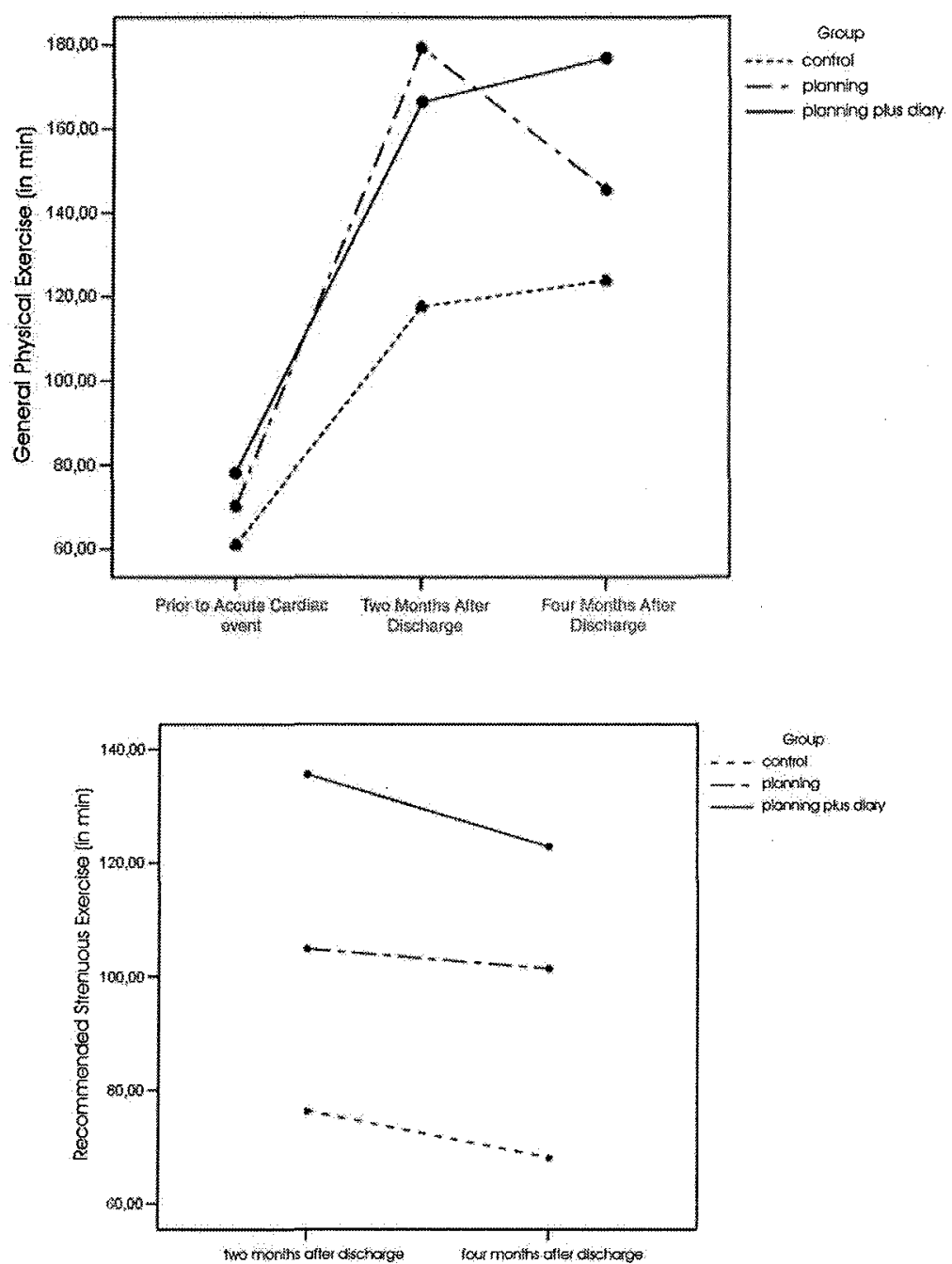

Figure 1. General physical exercise (in minutes per week) at Time 1, Time 2, and Time 3 and recommended strenuous exercise (in minutes per week) at Time 2 and Time 3 for control group, planning group, and planning plus diary group.

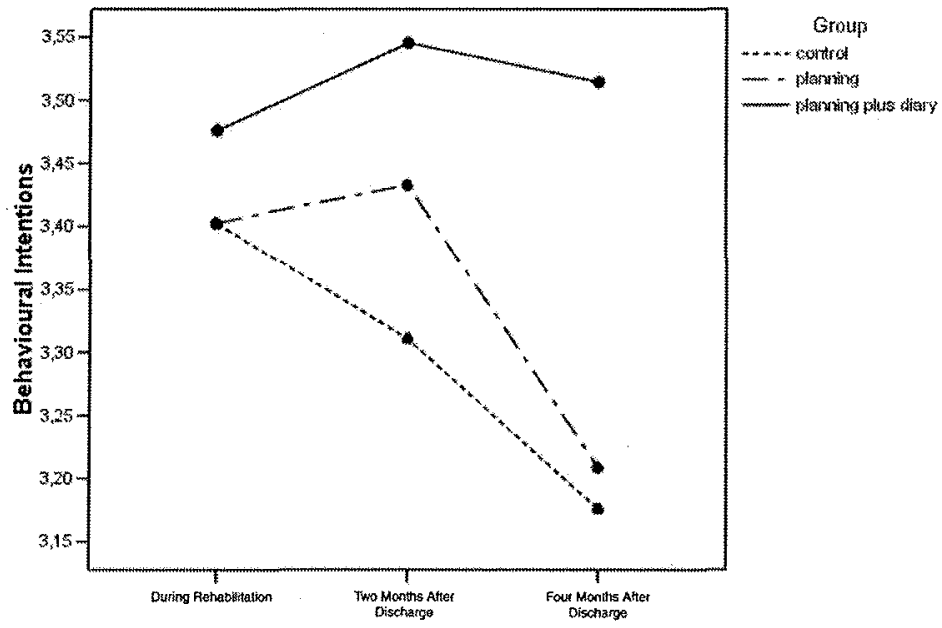

Figure 2. Behavioral intentions at Time 1, Time 2, and Time 3 for control group, planning group, and planning plus diary group. 
Table 3. Effects of Planning Treatments on Time 3 Recommended Strenuous Exercise, Controlling for Age, Sex, and (I) Self-Efficacy and Behavioral Intentions; (2) Coping Planning and Action Control

\begin{tabular}{|c|c|c|}
\hline & & Group \\
\hline \multicolumn{3}{|c|}{ Analysis I (motivational model) } \\
\hline Intentions & Self-Efficacy & \\
\hline$F(1,193)=37.30^{* *}$ & $F(1,193)=0.02$ & $F(2,193)=4.08^{*}$ \\
\hline \multicolumn{3}{|c|}{ Analysis 2 (volitional model) } \\
\hline Coping planning & Action control & \\
\hline$F(1,193)=7.84 * *$ & $F(1,193)=27.47 * *$ & $F(2,193)=2.91$ \\
\hline
\end{tabular}

Note. $* p<.05 . * *<.01$.

Table 4. Frequencies of Attenders and Nonattenders at Cardiac Training Groups Within the Experimental Groups

\begin{tabular}{lcccr}
\hline Coronary Training Group & Control Group & Planning Group & Planning Plus Diary Group & Sum \\
\hline Nonattenders & 56 & 40 & 37 & 133 \\
Attenders & $(70.9 \%)$ & $(71.4 \%)$ & $(56.9 \%)$ & 67 \\
Sum & 23 & 16 & 28 & $(43.1 \%)$ \\
\hline
\end{tabular}

Note. Column percentages in parentheses.

control on changes in physical exercise in CHD patients. The results provide evidence that both interventions, the planning intervention and the planning plus diary intervention, are useful means to enhance physical activity and adherence in cardiac rehabilitation patients who are motivated to do so. Augmenting planning interventions by keeping a diary within the first weeks after discharge results in higher levels of action control, more stable intentions, and a higher compliance to attend cardiac training groups. The long-term levels of exercise tend to be higher in the diary plus planning group, but these differences are not significant. Despite identical behavioral intentions and other motivational prerequisites in all groups, participants of both treatment groups profited from the brief interventions although they had already had the benefit of a comprehensive 3- to 4-week medical, psychological, and psychoeducational rehabilitation treatment. Planning may help individuals to transform their intentions into behavior and to cope successfully with difficulties. The positive effects of planning on goal attainment can be enhanced by active in situ action control. The latter one can be increased by keeping individually tailored diaries.

To meet the assumptions for statistical procedures, exercise measures were log-transformed. The natural logarithm squeezes larger values $(>1)$ together. The larger the values of the raw data are, the stronger their reduction in the log transformation. This study aimed to move sedentary individuals toward higher levels of activity. Therefore, in these analyses the effect sizes may have been underestimated due to the conservative test.

The long-term effect of the interventions on recommended strenuous exercise was fully mediated by ac- tion control and, to a lesser extent, by coping planning. This finding provides evidence that the mechanism underlying the interventions consisted of an increase in the volitional processes of action control and coping planning. The expected effects of the planning intervention on action planning, however, were not found. All participants reported high levels of elaboration in action planning. A closer analysis of the rehabilitation programs revealed that the participating rehabilitation centers had already included some aspects of action planning in their standard treatments. Thus, the intervention did not further contribute to the participants' action planning.

Group differences in behavioral intentions were found although the interventions had been designed to address postintentional volition processes. A post hoc analysis revealed that decreases in behavioral intentions as found in the control group can be prevented by interventions that address planning and action control. Although participants in the control group showed a linear reduction in intentions across the study period, participants in the planning group kept up their initial level of intentions after 2 months, and participants in the planning plus diary group showed a stable level of intentions over the entire 4 months. Thus, personal action control leads to the conservation and stability of one's intentions that are essential for further goal pursuit. Unstable intentions hinder successful goal striving (Bagozzi \& Yi, 1989; Conner, Sheeran, Norman, \& Armitage, 2000) and may be the result of unsuccessful action control (Sniehotta, Nagy, et al., in press). In this respect, the mediation of the experimental effects on general physical exercise at Time 3 can be interpreted as the result of a postintentional volitional process. 
This study has several limitations. The behavioral outcomes were assessed by self-reports. Although some studies indicate that self-report measures of physical exercise behavior are valid (Ainsworth et al., 2000; Bernstein et al., 1998), future research should augment self-reported exercise behavior by including objective measures (Stone \& Shiffman, 2002).

The components of the interventions (planning and keeping a diary) as well as the mediation processes, can be better evaluated in a research design incorporating pretest, posttest, and follow-up measures. This study did not include a posttest measure after the experimental treatment and therefore the effects of the treatment and the interaction of the effects with the experiences of the first weeks after discharge cannot be disentangled. Nevertheless, if the effects of the interventions persist for 2 months in which the rehabilitation patients had to readapt to their home setting and to implement their lifestyle changes, the effects must be strong and durable.

Finally, the study confounded keeping a diary and undergoing a planning intervention. Theoretically, it cannot be disentangled whether the observed long-term effects found for the planning plus diary group are the result of keeping a diary or the result of the interaction of planning (forming action plans and coping plans) and action control (keeping a diary). Further research should address action control independent from planning.

This study demonstrates the importance of the distinction between motivation and volition. Persons highly motivated to change their lifestyle can best be assisted by postintentional volitional interventions addressing action planning, coping planning, and action control.

\section{References}

Abraham, C., Sheeran, P., \& Johnston, M. (1998). From health beliefs to self-regulation: Theoretical advances in the psychology of action control, Psychology and Health, 13, 569-591.

Ades, P. A. (2001). Cardiac rehabilitation and secondary prevention of coronary heart disease. New England Joumal of Medicine, $345,892-902$.

Ainsworth, B. E., Sternfeld, B., Richardson, M. T., \& Jackson, K. (2000). Evaluation of the Kaiser physical activity survey in women. Medicine \& Science in Sports \& Exercise, 32 $1327-1338$

Ajzen, I. (1991). The theory of planned behavior. Organizational Behavior and Human Decision Processes, 50, 179-211.

American Psychological Association (APA). (2002). Ethical principles of psychologists and code of conduct. American Psychologist, 57, 1597-1611.

Bagozzi, R. P., \& Edwards, E. A. (2000). Goal setting and goal pursuit in the regulation of body weight. In P. Noman, C. Abraham, \& M. Conner (Eds.), Understanding and changing health behavior (pp. 261-297). Amsterdam: Harwood Academic.
Bagozzi, R.P., \& Yi, Y.(1989). The degree of formation as a moderator of the attitude-behavior relation. Social Psychology Quar. terly, 52, 913-929.

Bandura, A. (1997). Self-efficacy: The exercise of control. New York: Freeman.

Baumeister, R. F., Heatherton, T. F., \& Tice, D. (1994). Losing control: How and why people fail at self-regulation. San Diego, CA: Academic.

Bernstein, M., Sloutskis, D. Kumanyika, S., Sparti, A., Schutz, Y., \& Morabia, A. (1998). Data-based approach for developing a Physical Activity Frequency Questionnaire. American Joumal of Epidemiology, 147, 147-156.

Bjarnason-Wehrens, B., Mayer-Berger, W., Meister, E. R., Baum, K., Hambrecht, R., \& Gielen, S. (2004). Recommendations for resistance exercise in cardiac rehabilitation. Recommendations of the German Federation for Cardiovascular Prevention and Rehabilitation. European Journal of Cardiovascular Prevention and Rehabilitation, 11, 352-361.

Blanchard, C. M., Courneya, K. S., Rodgers, W. M., Daub, B., \& Knapik, G. (2002). Determinants of exercise intention and behavior during and after phase 2 cardiac rehabilitation: An application of the theory of planned behavior. Rehabilitation Psychology, 47, 308-323.

Bland, J. M., \& Altman, D. G. (1996). Statistical notes: Transforming data. British Medical Joumal, 3I2, 770 .

Carver, C. S., \& Scheier, M. F. (1998). On the self-regulation of behavior: New York: Cambridge University Press.

Conner, M., \& Armitage, C. J. (1998). The theory of planned behavior: A review and avenues for further research. Journal of $A p$ plied Social Psychology, 28, 1430-1464.

Conner, M., Sheeran, P., Norman, P., \& Armitage, C. J. (2000). Temporal stability as a moderator of relationships in the theory of planned behaviour. British Journal of Social Psychology, 39, 469-493.

De Backer G., Ambrosioni E., Borch-Johnsen K., Brotons, C Cifkova, R., Dallongeville, J., et al. (2003). Third Joint Task Force of European and Other Societies on Cardiovascular Disease Prevention in Clinical Practice. European guidelines on cardiovascular disease prevention in clinical practice. European Heart Joumal, 24, 1601-1610.

Deutsche Gesellschaft für Kardiologie [German Cardiac Society] (2001). Empfehlungen zur umfassenden Risikoverringerung für Patienten mit koronarer Herzerkrankung [Recommendation for comprehensive risk reduction in cardiac patients]. Zeitschrift fiir Kardiologie, 90, 148-149.

Dietz, R., \& Rauch, B. (2003). Guidelines for the diagnosis and treatment of chronic coronary heart disease. Issued by the executive committee of the German Society of Cardiology - Heart Circulation Research in cooperation with the German Society for Prevention and Rehabilitation of Cardiac Diseases and the German Society for Thoracic and Cardiovascular Surgery. Zeitschrift fuer Kardiologie, 92, 501-521.

Donker, F. J. S. (2000). Cardiac rehabilitation. A review of current developments. Clinical Psychology Review, 20, 923-943.

Dusseldorp, E., Van Elderen, T., Maes, S., Meulman, J., \& Kraaij, V. (1999). A meta-analysis of psychoeducational programs for coronary heart disease patients. Health Psychology, I8, 506-519.

Fuchs, R. (1997). Psychologie und körperliche Bewegung. Grundlagen für theoriegeleitete Interventionen [Psychology and physical activity. Foundations for theory-based interventions]. Göttingen, Germany: Hogrefe.

Gollwitzer, P. M. (1999). Implementation intentions. Strong effects of simple plans. American Psychologist, 54, 493-503.

Gollwitzer, P. M., \& Oettingen, G. (1998). The emergence and implementation of health goals. Psychologyand Health, 13, 687-715.

Grundy, S. M., Paternak, R., Greenland, P., Smith, S., Jr., \& Fuster, V. (1999). Assessment of cardiovascular risk by use of multi- 
ple-risk-factor assessment equations. A statement of healthcare professionals from the American Heart Association and the American College of Cardiology. Circulation, 100, 1481-1492.

Johnston, D. W. (1999). Lifestyle changes after a myocardial infarction. Heart, 82, 243-244.

Johnston, D. W., Johnston, M., Pollard, B., Kinmonth, A. L., \& Mant, D. (2004). Motivation is not enough: Prediction of risk behavior following diagnosis of coronary heart disease from the theory of planned behavior. Health Psychology, 23, 533-538.

Jolliffe, J. A., Rees, K., Taylor, R. S., Thompson, D., Oldridge, N., \& Ebrahim, S. (2003). Exercise-based rehabilitation for coronary heart disease (Cochrane Methodology Review). In The Cochrane library, 4. Chichester, UK: Wiley.

Kanfer, F. H., \& Karoly, P. (1982). The psychology of selfmanagement: Abiding issues and tentative directions. In P. Karoly \& F. H. Kanfer (Eds.), Self-management and behavior change from theory to practice (pp. 571-599). New York: Pergamon.

Kuhl, J. (1986). Motivation and information processing: A new look at decision making, dynamic change, and action control. In $\mathrm{R}$. M. Sorrentino \& E. T. Higgins (Eds.), Handbook of motivation and cognition: Foundation of social behavior (pp. 404-434). New York: Guilford.

Leventhal, H., Singer, R., \& Jones, S. (1965). Effects of fear and specificity of recommendation upon attitudes and behavior. Joumal of Personality and Social Psychology, 2, 20-29.

Lippke, S., Ziegelmann, J. P., \& Schwarzer, R. (2004). Behavioral intentions and action plans promote physical exercise: A longitudinal study with orthopedic rehabilitation patients. Joumal of Sport and Exercise Psychology, 26, 470-483.

Milne, S., Orbell, S., \& Sheeran, P. (2002). Combining motivational and volitional interventions to promote exercise participation: Protection motivation theory and implementation intentions. British Joumal of Health Psychology, 7, 163-184.

Mischel, W., Shoda, Y., \& Peake, P. K. (1988). The nature of adolescent competencies predicted by preschool delay of gratification. Joumal of Personality and Social Psychology, 54, $687-696$.

Moore, S. M., Ruland, C. M., Pashkow, F. J., Blackburn, G. G. (1998). Women's patterns of exercise following cardiac rehabilitation. Nursing Research, 47, 318-324.

Muraven, M., Baumeister, R. F., \& Tice, D. M. (1999). Longitudinal improvement of self-regulation through practice: Building self-control strength through repeated exercise. Journal of Social Psychology, 139, 446-457.

Murgraff, V., White, D., \& Phillips, K. (1996). Moderating binge drinking: It is possible to change behaviour if you plan it in advance. Alcohol and Alcoholism, 31, 577-582.

Oldridge, N. B. (1991). Cardiac rehabilitation services: What are they and are they worth it? Comprehensive Therapy, 17, $59-66$.

Ornish, D., Schweritz, L. W., Billings, J. H., Brown, S. E., Gould, K. L., Merritt, T. A., et al. (1998). Intensive lifestyle changes for reversal of coronary heart disease. Joumal of the American Medical Association, 280, 2001-2007.

Scheier, F. M., \& Carver, C. S. (2003). Self-regulatory processes and responses to health threat: Effects of optimism on well-being. In J. Suls \& K. A. Wallston (Eds.), Social psychological foundations of health and illness (pp. 395-428). Oxford, England: Blackwell.

Schröder, K. E. E, \& Schwarzer, R. (2005). Habitual self-control and the management of health behavior among heart patients. Social Science and Medicine, 60, 859-875.

Schwarzer, R. (1992). Self-efficacy in the adoption and maintenance of health behaviors: Theoretical approaches and a new model. In R. Schwarzer (Ed.), Self-efficacy: Thought control of action (pp. 217-242). Washington, DC: Hemisphere.

Sheeran, P., \& Orbell, S. (1999). Implementation intentions and repeated behaviour: Augmenting the predictive validity of the theory of planned behaviour. European Journal of Social Psy. chology, 29, 349-369.

Sniehotta F. F., Nagy, G., Scholz, U., \& Schwarzer, R. (in press). The role of action control in implementing intentions during the first weeks of behaviour change. British Joumal of Social Psychology.

Sniehotta, F. F, Scholz, U., \& Schwarzer, R. (2005). Bridging the intention-behaviour gap: Planning, self-efficacy, and action control in the adoption and maintenance of physical exercise. Psy. chology \& Health, 20, 143-160.

Sniehotta, F. F., Scholz, U., \& Schwarzer, R. (in press). Action planning and coping planning for physical exercise: A longitudinal intervention study in cardiac rehabilitation. British Joumal of Health Psychology.

Sniehotta, F. F., Schwarzer, R., Scholz, U., \& Schüz, B. (2005). Action planning and coping planning for long-term lifestyle change: Theory and assessment. European Joumal of Social. Psychology, 35, 565-576.

Stone, A. A., \& Shiffman, S. (2002). Capturing momentary self-report data: A proposal for reporting guidelines. Annals of Behavioral Medicine, 24, 236-143.

Sutton, S. (1998). Predicting and explaining intentions and behavior: How well are we doing? Joumal of Applied Social Psychology, $28,1317-1338$.

Thompson, P. D., Buchner, D., Piña, I. L., Balady, G. J., Williams, M A., Marcus, B. H., et al . (2003). Exercise and physical activity in the prevention and treatment of atherosclerotic cardiovascular disease. Circulation, 107, 3109-3116.

Verplanken, B., \& Faes, S. (1999). Good intentions, bad habits and the effects of forming implementation intentions on behavior and cognition. European Joumal of Social Psychology, 29, $591-604$.

Willich, S. N., Muller-Nordhorn, J., Kulig, M., Binting, S., Gohlke, H., Hahmann, H., et al. (2001). Cardiac risk factors, medication, and recurrent clinical events after acute coronary disease; a prospective cohort study. European Heart Journal, 22, 276-279. 